\title{
因HAD
}

ISSN-L: 2530-5115

DOI: http://doi.org/10.22585/hospdomic.v4i2.104

\section{Derivación a hospitalización a domicilio de pacientes con infección por COVID-19}

\section{Referral to Home Care of Patients with COVID-19 Infection}

Abel Mujal Martínez', José Regalado de los Cobos², María Ruiz Castellano3, Manuel Mirón Rubio ${ }^{4}$, Andima Basterretxea Ozamiz ${ }^{5}$, Oriol Estrada Cuxart ${ }^{6}$, Magdalena Fernández Martínez de Mandojana ${ }^{7}, M{ }^{a}$ Montserrat Gómez Rodríguez de Mendarozqueta ${ }^{8}$, Miguel Angel Ponce González ${ }^{9}$, Ana María Torres Corts ${ }^{10}$, Carmina Wanden-Beghe"11, Beatriz Massa Domínguez ${ }^{12}$

1. Hospital Universitari Parc Taulí. Sabadell, España.

2. OSI Araba. Vitoria-Gasteiz, España.

3. Complejo Hospitalario de Navarra. Pamplona, España.

4. Hospital Universitario de Torrejón, Torrejón de Ardoz, España.

5. Hospital Universitario Cruces. Barakaldo, España.

6. Hospital Universitari Germans Trias i Pujol. Badalona, España.

7. OSI Debabarrena Guipuzkoa. Donostia-San Sebastian, España.

8. Hospital Universitario Araba. Vitoria-Gasteiz, España.

9. Hospital Universitario de Gran Canaria Doctor Negrín. Las Palmas de Gran Canaria, España.

10. Hospital Dos de Maig. Barcelona, España.

11. Hospital General Universitario de Alicante. Alicante, España.

12. Departamento Salud de Alicante. Sant Joan d'Alacant, España.

Recibido/Received

29.03.2020

Aceptado/Accepted

2.04.2020

CÓMO CITAR ESTE TRABAJO | HOW TO CITE THIS PAPER

Mujal A, Regalado J, Ruiz M, Mirón M, Basterretxea A, Estrada O, et al. Derivación a hospitalización a domicilio de pacientes con infección por COVID-19. Hosp Domic. 2020;4(2):59-67. 


\section{DEFINICIÓN}

La Hospitalización a Domicilio (HAD) es una alternativa asistencial del Área de Salud consistente en un modelo organizativo capaz de dispensar a pacientes en su propio domicilio un conjunto de actividades y cuidados sanitarios con complejidad, intensidad y duración comparables a los de una hospitalización convencional cuando todavía precisan de una vigilancia activa y una asistencia compleja.

\section{JUSTIFICACIÓN}

El nuevo coronavirus COVID-19 causa una enfermedad infecciosa aguda con un amplio abanico de manifestaciones clínicas, así como un rango de severidad que va desde casos leves hasta fracaso multiorgánico y éxitus del paciente. En poco tiempo, han aparecido un elevadísimo número de pacientes que sobrepasan la capacidad asistencial habitual de los centros hospitalarios, así como de los recursos proporcionados por Atención Primaria.

En el contexto epidemiológico actual de la infección por COVID-19 en España con el progresivo aumento de los casos sintomáticos en las próximas semanas, la Sociedad Española de Hospitalización a Domicilio (SEHAD) se plantea como una opción en el manejo de estos pacientes. Entre los beneficios de la incorporación de esta modalidad asistencial están:

- Permite disponibilidad de camas para aquellos casos más graves y que precisan hospitalización.

- Minimiza el número de contactos de trabajadores sanitarios con el paciente.

- Disminuye los costes del ingreso hospitalario y de material de aislamiento.

- El paciente es aislado y tratado en su entorno domiciliario, recibiendo un trato más personalizado y proporcionándole durante el ingreso mayor intimidad, comodidad y bienestar a la vez que se favorece el autocuidado.

- Se integra a los cuidadores en el proceso asistencial, proporcionándoles mejor información y educación sanitaria y evitándoles desplazamientos al hospital.

- Disminuye las infecciones nosocomiales, síndromes confusionales y el deterioro funcional en los pacientes mayores durante el ingreso.

Ya son varias las comunidades autónomas que han implicado a la HAD en sus dispositivos de atención a pacientes con coronavirus o que han incluido a estas Unidades en los planes de contingencia de algunos de sus centros asistenciales.

\section{ORIGEN DE LOS PACIENTES}

Los pacientes con sospecha o infección confirmada por COVID-19 que accedan a HAD pueden tener distintas procedencias:

- Pacientes que reciben atención domiciliaria por parte de atención primaria.

- Pacientes procedentes del Servicio de Urgencias.

- Pacientes asistidos en hospitales de día o en consultas externas. 
- Pacientes ingresados en hospitalización convencional.

- Pacientes ingresados por otro motivo en HAD.

\section{CRITERIOS GENERALES DE INGRESO EN HAD}

Los enfermos susceptibles de ingresar en HAD deben cumplir los siguientes requisitos:

- Proceso asistencia que pueda dispensarse en el domicilio.

- Aceptación voluntaria del paciente y sus potenciales cuidadores del ingreso en HAD.

- Existencia de una persona (familiar o contratada) que sea identificable como cuidador principal y que sea capaz de realizar funciones de apoyo al personal sanitario:

- Cuidado directo del paciente (aseo, alimentación...).

- Control, administración y seguimiento de la medicación oral.

- Opcionalmente y de forma voluntaria colaboración en la administración de medicación por otras vías (subcutánea, intravenosa, aerosoles, etc.).

- Realización de técnicas sencillas (glucemias, temperatura, pulsioximetría, ...).

- Vivienda adecuada: condiciones de salubridad. Línea telefónica.

- Residencia del paciente en el área de cobertura de la HAD correspondiente.

- Paciente sin hábitos tóxicos activos (drogodependencia, alcoholismo).

\section{REQUISITOS MÍNIMOS PARA LA HOSPITALIZACIÓN A DOMICILIO}

Los pacientes con infección por COVID-19 que ingresen en HAD, asimismo deberán cumplir con los requisitos establecidos por el Ministerio de Sanidad, Consumo y Bienestar Social para la atención domiciliaria:

- La vivienda debe disponer de una estancia con buena ventilación y que pueda ser dedicada de forma específica para el aislamiento del caso, con posibilidad de designar un baño para uso exclusivo del paciente o, en su defecto, deberá ser limpiado con lejía doméstica tras su uso.

- Disponibilidad por parte del caso de un terminal telefónico que garantice la comunicación permanente con el personal sanitario hasta la resolución de los síntomas.

- Independientemente de que cada caso se deba valorar de forma individual, como norma general no deberá haber convivientes con condiciones de salud que supongan una vulnerabilidad: personas con edad avanzada, deterioro funcional, enfermedades crónicas, inmunodeprimidas, embarazadas. Tanto el paciente como sus convivientes deberán ser capaces de comprender y aplicar de forma correcta y consistente las medidas básicas de higiene, prevención y control de la infección.

- En el caso de que las viviendas de los pacientes no reúnan las condiciones exigibles para realizar el aislamiento de forma adecuada, podrán ser atendida por la unidad de HAD en lugares específicamente habilitados para ello por las administraciones sanitarias correspondientes: hoteles, cuarteles, residencias, etc... desarrollando para ello protocolos de actuación apropiados. 


\section{CRITERIOS ORIENTATIVOS PARA EL INGRESO EN HAD}

\section{1.- Modelo de alta precoz: pacientes ingresados por neumonía por COVID-19 que presenten buena evolución}

- Buena evolución clínica ( $F C<100$ x ', FR <24 x', descenso de fiebre y defervescencia clínica).

- Saturación $\mathrm{O}_{2}$ basal> 90\% o igual a la previa a la infección

- No deterioro del nivel de conciencia

- Mejoría analítica (linfopenia, PCR y biología hepática)

- Sería recomendable la práctica de una radiografía de control pre-alta que muestre mejoría/ resolución de los infiltrados pulmonares.

- Valorar el traslado a HAD de pacientes con mala evolución en los que todas las partes implicadas asumen la implementación de cuidados paliativos en domicilio

\section{2.- Modelo de evitación del ingreso}

- Serán candidatos a ingreso directo en UHD desde el servicio de urgencias:

- Los pacientes con neumonía leve o moderada (CURB<2, Sat >90\%) SIN factores de riesgo (HTA, DM, obesidad, EPOC, cardiopatía isquémica, inmunosupresión, edad>60 años)

- De forma individualizada, se podrán valorar pacientes CON factores de riesgo con cuadro de infección respiratoria alta (sin infiltrados neumónicos) que por situación de especial fragilidad se desestime el seguimiento sólo por Atención Primaria.

- Para que el paciente sea admitido en HAD debe cumplir TODOS los criterios de ingreso siguientes:

Situación clínica de estabilidad, definida por los siguientes criterios:

\begin{tabular}{|l|l|}
\hline Constante & Valores de estabilidad \\
\hline Frecuencia cardiaca & $<100 \mathrm{lpm}$ \\
\hline Frecuencia respiratoria & $<24 \mathrm{RPM}$ \\
\hline Presión arterial sistólica & $>90 \mathrm{mmHg}$ \\
\hline Saturación $\mathrm{O}_{2}$ basal & $>90 \%$ si no había insuficiencia respiratoria previa \\
\hline Nivel de consciencia & Adecuado \\
\hline
\end{tabular}

Ausencia de signos de gravedad en analítica:

\begin{tabular}{|l|l|}
\hline Determinación & Valores de estabilidad \\
\hline Linfocitos & $>500$ \\
\hline LDH & $<800$ \\
\hline D dímero & $<1000$ \\
\hline
\end{tabular}




\section{LUGAR DE AISLAMIENTO EN EL DOMICILIO}

- El paciente deberá permanecer preferiblemente en una estancia o habitación de uso individual o, en caso de que esto no sea posible, en un lugar en el que se pueda garantizar una distancia mínima de 2 metros con el resto de los convivientes. La puerta de la habitación deberá permanecer cerrada. En caso de que sea imprescindible ir a las zonas comunes del domicilio deberá utilizar mascarilla quirúrgica y realizar higiene de manos al salir de la habitación. Se mantendrán bien ventiladas las zonas comunes.

- La habitación deberá tener una ventilación adecuada directa a la calle, no deben existir corrientes forzadas de aire provenientes de sistemas de calor o refrigeración.

- Deberá disponer de un baño para uso exclusivo del paciente o, en su defecto, deberá ser limpiado con lejía doméstica tras cada uso.

\section{PROCEDIMIENTO DE ATENCIÓN EN EL DOMICILIO}

Los profesionales de HAD tomarán las medidas de protección indicadas en el protocolo del Salud Pública de cada comunidad autónoma a la que pertenezcan: higiene de manos y colocación del equipo de protección individual - EPI (Anexo 1) (bata, mascarilla FPP2/FPP3, guantes y protección ocular antisalpicaduras). El equipo de HAD se pondrá el EPI en una zona del domicilio que se determine como "zona limpia" fuera del contacto con el paciente. Se llevarán diariamente los equipos de protección y no se dejará material de aislamiento en el domicilio.

La visita de HAD se realizará en la habitación de aislamiento y, durante todo el tiempo que dure la misma, tanto el paciente como el cuidador deberán llevar la mascarilla quirúrgica

Tras la asistencia al paciente el EPI que use el personal sanitario se retirará en el interior de la habitación de aislamiento a excepción de las gafas y la mascarilla, que se retirarán fuera de la misma. Las gafas y la mascarilla se introducirán en una bolsa hermética y se llevarán de vuelta al hospital. Una vez en la Unidad, la mascarilla se eliminará como un residuo biosanitario de clase II y las gafas se limpiarán adecuadamente para poder ser reutilizadas.

Se realizará una estricta higiene de manos después del contacto con el paciente y de la retirada del EPI.

De forma general, se evitarán procedimientos que generen aerosoles en el domicilio del paciente. En caso de ser necesarias nebulizaciones, se indicará al paciente su realización cuando se encuentre solo en la habitación de aislamiento con la puerta cerrada y la correcta ventilación de esta al finalizar. Se le indicará expresamente la realización de dichas nebulizaciones fuera del horario de visita de HAD.

En caso de que el paciente precise de oxigenoterapia o compresor para nebulizaciones serán suministrados por el equipo de HAD, junto con la documentación informativa.

En la habitación de aislamiento del paciente se dejará un equipo de tensiómetro durante todo el procedimiento. Todo el material como fonendoscopios, otoscopios.... que se introduzca en la habitación de aislamiento deberá limpiarse según las recomendaciones de los servicios de salud de las comunidades autónomas correspondientes.

En caso de que el paciente este pendiente del resultado y se acuda al domicilio, se tomarán estas mismas precauciones hasta la confirmación del resultado. 


\section{ALTA DE HAD}

Criterios de alta de los pacientes con COVID-19 de HAD hacia Atención Primaria:

- Ausencia de fiebre durante 72 horas

- Analítica de control con mejoría (linfopenia, PCR, D-dímero, +/- LDH y ferritina)

- Saturación $\mathrm{O}_{2} \geq 94 \%$

- Mejoría de síntomas y del estado general.

No es necesario prolongar el ingreso en HAD hasta haber terminado el período de aislamiento. Se darán instrucciones de cómo y hasta cuándo se debe mantener.

Se hará informe de alta detallando estas instrucciones y se comunicará a Atención Primaria.

\section{REINGRESO AL HOSPITAL}

Si la evolución del paciente en el domicilio es desfavorable y hay traslado al hospital, se valorará por el equipo de HAD. 


\section{ANEXO-1}

En los domicilios donde haya pacientes con sospecha o confirmación de coronavirus SARS-CoV-2, los profesionales asistenciales de HAD permanecerán durante toda su asistencia con el siguiente equipamiento de protección:

- Bata de microfibra o impermeable (o bata de aislamiento verde desechable y delantal plástico de un solo uso)

- Mascarilla FFP2 / FFP3

- Mascarilla quirúrgica (desechable)

- Gorro (desechable)

- Guantes de protección (desechables)

- Gafas de protección (reutilizables una vez limpiadas con desinfectante)

\section{En el hospital:}

Antes de ir al domicilio se realizará llamada telefónica para verificar la dirección y datos del paciente.

Se preparará el material necesario para cada paciente (EPI), bolsita con toallitas con solución desinfectante, bolsa o contenedor de plástico para residuos, solución alcohólica... y se identificará todas las posibles muestras (tubos de analíticas, frotis ...) del paciente rotulados. Importante llevar las bolsas "zip" para introducir las muestras y el envase de transporte.

\section{En el domicilio:}

- Se cogerá el material necesario (el material que se pueda se enfundará) y se subirá al rellano de la puerta del domicilio.

- En el rellano del domicilio el profesional sanitario se retirará joyas, relojes y objetos colgantes.

- Se hará lavado de manos con solución alcohólica.

- Se colocará el equipo de protección individual (EPI): bata impermeable, mascarilla FFP2 / FFP3, mascarilla quirúrgica (que se colocará encima de la FFP2 / FFP3), gafas de protección, gorro y guantes de nitrilo que cubrirán el puño de la bata. 


\section{Secuencia para ponerse el equipo de protección individual (EPI)}

Fuera de la vivienda (rellano del domicilio):

1. Higiene de manos con solución hidro-alcohólica

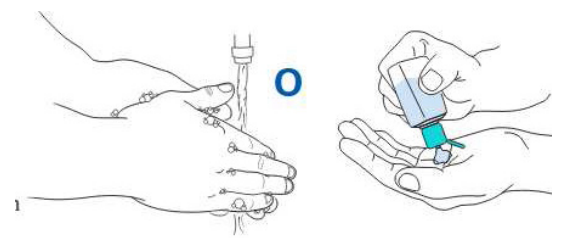

2. Bata impermeable: Cubrir con la bata todo el torso desde el cuello hasta las rodillas, los brazos hasta las muñecas, y ligarse a por último a la altura del cuello y la cintura

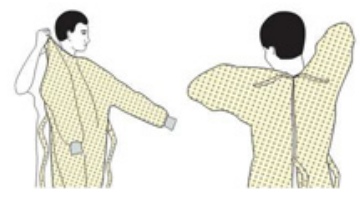

3. Mascarilla FFP2 / FFP3 y mascarilla quirúrgica: Poner mascarilla FFP2 / 3 y encima una mascarilla quirúrgica para proteger la otra mascarilla. La mascarilla quirúrgica se renovará cada visita.

4. Gafas protectoras: Colocar la foto sobre la cara y los ojos y ajustarla
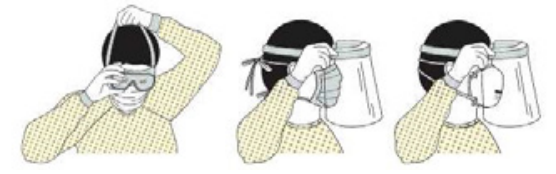

5. Higiene de manos con solución hidroalcohólica

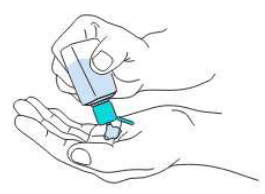

6. Colocación de guantes: Extender los guantes para que cubran la parte del puño de la bata de aislamiento

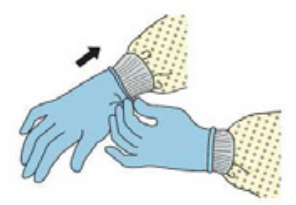




\section{Entrar en el domicilio:}

- Al entrar en el domicilio se procurará no tocar nada que no sea estrictamente necesario, siempre que sea posible el paciente saldrá de la habitación para la realización de la visita.

- Se proporcionará al paciente una mascarilla quirúrgica, que se deberá colocar.

- Se dará al paciente hoja informativa de las medidas de aislamiento en el domicilio.

- Una vez finalizada la asistencia en el domicilio, nos acercaremos a la salida y se hará la retirada rigurosa del equipo de protección individual.

- Antes de retirar los EPI dejaremos el material asistencial pendiente de limpiar en una bolsa negra (fonendoscopio, pulsioxímetro, ...).

\section{Salida del domicilio:}

- La retirada de la bata desechable se hará conjuntamente con los guantes y se hará bola del material, dejándolos en una bolsa o contenedor para residuos.

- Higiene de manos con solución alcohólica.

- La mascarilla quirúrgica se retirará de detrás de la goma adelante y se lanzará a la bolsa negra.

- Las gafas de protección las retiraremos desde detrás de la goma hacia delante, la dejaremos en otro bolso junto con el material que se ha utilizado en la exploración del paciente para luego limpiarlo con toallita o solución desinfectante.

- Todo el material desechable se dejará en bolsa o contenedor para residuos que posteriormente será llevado al contenedor de basura no reciclable (gris).

\section{Fuera del domicilio:}

- Nos limpiaremos las manos con solución alcohólica y nos retiraremos la mascarilla FFP2/ FFP3.

- Limpiaremos el material asistencial con toallitas o solución desinfectante (nos pondremos guantes de un solo uso).

- Una vez limpio el material, retiramos guantes y se hará higiene de manos. 